\title{
Evaluating Design Project Creativity in Engineering Design Courses
}

\author{
I. Chiu \\ Postdoctoral Fellow \\ Department of Mechanical and Industrial \\ Engineering \\ Ryerson University \\ ivey.chiu@ryerson.ca
}

\author{
F. A. Salustri \\ Associate Professor \\ Department of Mechanical and Industrial \\ Engineering \\ Ryerson University \\ salustri@ryerson.ca
}

\begin{abstract}
Creativity is integral to design success, yet creativity is not well-defined nor easily evaluated. A goal of engineering design courses is to teach creativity, or at least creativity methods, e.g., brainstorming, random stimuli, etc., that when applied, should increase design creativity. However, it is unclear how creativity outcomes can be evaluated, or even if creativity should be evaluated within an engineering design course, such as for a design project. In this paper, we discuss creativity and approaches to evaluating creativity using both the literature and our experiences with evaluating design project creativity. We also describe future work required to further understand and develop methods of evaluating design project creativity with the aim of encouraging students to consciously work towards creative designs.
\end{abstract}

\section{Introduction}

Creativity has been acknowledged as an integral part of design and engineering [1][2][3]. Some researchers have even argued that design necessarily involves creativity [4]. On a practical level, creativity is a measure of design success and can be consider an "order winner." While customers will voice functional and performance requirements, e.g., cargo space, fuel efficiency, creativity will often remain an unvoiced requirement [5], even though the more creative and innovative products will be selected. As such, creativity is highly valued in engineering as well as in business and industry [6][7]. This appears to indicate that creativity should be an important part of engineering education and an important student outcome.

In engineering design, creativity can be implicitly taught through presenting methods that were developed specifically to increase concept creativity, such as brainstorming, TRIZ (the Russian acronym for the Theory of Inventive Problem Solving), random stimuli, etc. [8-10]. Often, students are either encouraged or required to apply these creative concept generation methods within the design project component of an engineering design course; presumably to come up with creative designs.

However, because creativity is difficult to define and measure, it may also be difficult to measure creativity as a student outcome. After all, how can creativity be evaluated when there is no agreed-upon definition? Another concern is that assessment, and especially a creativity assessment, may suppress future performance and creativity because of preoccupations with the instructor's expectations [11]. However, because there is evidence that enhanced creativity combined with high academic performance may lead to increased design quality and innovativeness [12], appropriate evaluation of creativity outcomes, and appropriate use of creativity outcomes as feedback, may facilitate more creative design.

In the rest of this paper, we will first examine creativity definitions and metrics, and then review the literature to compare how other engineering courses evaluate design project creativity and include the evaluation within the grading framework. We will focus on evaluating design project creativity because many design courses include a design project component of a significant length, and because design projects can approximate "real life" design problems. We will then describe and discuss our experiences in evaluating design project creativity using both peer and expert evaluation. Finally, we will describe future work required to further understand how design project creativity is evaluated so that appropriate methods can be developed and applied. 


\section{Definitions and Measures of Creativity}

While creativity is difficult to define and pinpoint, creativity is generally regarded as a recognizable entity; something that you recognize when you "see it" [13] [14]. Many researchers regard creativity as involving the synthesis of a whole from different, and often unrelated parts [15-17]. This may involve finding relationships [10][15][17], or manipulating and applying transformations [16] to these different and unrelated parts. There is agreement that these "parts" include information and knowledge, which are elements also crucial to design.

As mentioned previously, there is general agreement that creativity is essential to design $[1][4][5][10]$ and valued in engineering and engineering education [1][2][18-20].

\subsection{Measuring Creativity}

While there are also disagreements about how to measure design creativity, many creativity researchers agree that creativity is multidimensional. For a design to be creative, it must be both novel and useful. A novel design is new, original or surprising [1][21][22], and a useful design is appropriate, functional, correct and valuable [10][15][23][24]. Others contend that creative designs must also include properties such as detail and elegance [21] [23]. However there is no agreement on these creativity measures, and some consider novelty and usefulness to be the only measures of creativity [15] [24].

Within engineering, there is certainly emphasis on the usefulness measure with regards to creativity [2][3][25]. Ullman [3] specifies that creative ideas must be more than just good ideas; they must solve the problem. De Bono [10] stresses that creative ideas include an underlying logic and value in addition to novelty. Ideas that are merely novel may be "bizarre," strange, or even incorrect.

\subsection{Evaluating Engineering Design Creativity}

There is ample literature on creativity in engineering education, however, surprisingly, the literature on evaluating creativity within engineering education is sparse. Based on the literature, there is certainly evidence that creativity is valued and taught in engineering design courses [18][19][20][26][27]. However, few specifically discuss methods of evaluating creativity and design project creativity as part of the course outcome.

Charyton and Merrill [18] describe the development of an engineering-specific test for assessing creativity and creative design skills of first- year engineering students. However, this test is not related to a specific course component or student outcome. Both [20] and [27] describe courses with the objective of increasing creative design and [27] include a graded creativity component for the design project. However, [27] do not detail the method in which design project creativity is evaluated. An author of this paper has been involved with first-year and fourth-year design courses at the University of Toronto. In one of the first-year courses, the grading rubric specifies work that is "highly original" would "exceed requirements," but a specific grade is not assigned to design originality, nor is a method of determining design originality specified. Later in this paper, we will describe and discuss the same author's experiences with incorporating a graded creativity component into a fourth-year design course.

There are several approaches to evaluating project creativity. Instructor, peer and expert evaluation [14][26] have all been documented as methods for evaluating technical projects in the areas of architecture, electronics, software and marketing design.

In assessing creativity in architectural design, [14] employed both instructor and peer assessment. The instructor evaluated creativity by specifying that "the more creative and original the design solution, the higher the grade." Peers evaluated project creativity by voting for projects based on creativity as they "s[aw] it." Project creativity was then based on the total number of peer votes received. Betz [14] found a high correlation between peer and instructor assessments of creativity and concluded that it is possible to assess design project creativity despite the ambiguity of creativity.

Waks and Merdler [26] recruited expert evaluators to assess creativity in electronics, software and marketing design projects. The experts watched recorded project presentations and completed a survey consisting of eight questions related to aspects of creativity, including integration of non discipline specific knowledge, integration of discipline specific knowledge, originality and usefulness. Waks and Merdler [26] observed that definitions of creativity were somewhat discipline dependent, for example, in electronics engineering, novelty appeared dependent on usefulness, which is consistent with many of the engineering views of creativity, e.g., [3].

From [14] and [26], it is possible to see that a range of creativity definitions and measures can be applied for evaluation purposes; from a loose definition of creativity, to a very specific definition. Our experiences with evaluating design project creativity involved a simple but structured approach based on the commonly agreed measures of creativity, novelty 
and usefulness. In the following sections, we will describe our experiences and observations with expert and peer evaluation of design project creativity in a fourth-year design class.

\section{Method}

Participants consisted of 66 students in a fourth-year design class in the Department of Mechanical and Industrial Engineering at the University of Toronto. Students were divided into 13 project groups consisting of three to seven members per group. Students worked on one of two projects: the multipurpose family furniture project that was sponsored by a major Canadian retailer ("retailer project"), and the commuter cyclist project to encourage more people to cycle to work or school in Toronto ("cycling project").

Students worked on projects throughout the term, incorporating various design techniques taught in lecture. These techniques included House of Quality, for relating customer requirements to engineering specifications, Pugh's method, for concept evaluation, as well as specific creativity and concept generation techniques such as brainstorming, 6-3-5, TRIZ, random stimuli and biomimetic design. Creativity was also discussed in lecture, specifically Wallas' model of creativity, definitions of creativity, and creativity measures, i.e., novelty and usefulness.

Projects culminated in a project report and a presentation. Presentations were graded by a panel of teaching assistants and the instructor. Project reports were graded by the instructor. Presentations and reports were graded for organization, clarity, evidence of research, etc., and did not include a creativity component. The peer creativity component was worth $2 \%$ the total term grade, and the presentation and report were worth $5 \%$ and $13 \%$ of the total term grade respectively.

During the project presentations, two experts from the major Canadian retailer judged and ranked the projects sponsored by the retailer. There was no cycling industry expert present. Student groups were assigned to evaluate projects of the same type, i.e., members of cycling project groups only evaluated cycling projects. More details regarding the expert and peer creativity evaluations methods are given below.

\subsection{Expert Evaluation Method}

Two experts from the sponsoring retailer attended the final design presentations of the seven groups involved with the retailer project. One of the experts had presented the initial design problem and had been involved with the project throughout the term, e.g., midterm design review. This expert has an engineering background and both experts were members of the retailer's Product Development Group.

Both experts watched all seven project presentations and provided feedback to the groups. Afterwards, the experts ranked all of the groups considering novelty and usefulness, and produced a single overall list of projects ranked from the most creative to least creative by consensus. Expert rankings were not factored into the term grade, however, prizes were awarded to the top two teams.

\subsection{Peer Evaluation Method}

Students were assigned to evaluate a specific group and were provided with evaluation forms and evaluated the designs using the following guidelines:

1. Novelty - does this design appear new, surprising, original? $0=$ not novel, $5=$ very novel.

2. Usefulness - does this design appear useful, valuable, functional? $0=$ not useful, $5=$ very useful.

Space was also provided for comments. The final novelty and usefulness ratings were calculated by averaging all the student ratings for that project. The ratings were reduced to a grade worth $1 \%$ for each measure, and the sum of the novelty and usefulness grade contributed to $2 \%$ of the final term grade.

\section{Observations and Results}

In this section, we will first describe some of the qualitative observations and feedback obtained from the evaluation process. Then, we will present some quantitative comparisons between the different evaluation methods.

In general, students were accepting of peer creativity evaluation and its inclusion into the final term grade. This was despite some of the reservations expressed earlier in the term when the general topic of creativity was presented in lecture. Some students expressed scepticism that creativity can be defined and measured, especially in an engineering context. Despite earlier reservations, students appeared to find the actual evaluation process straightforward and unambiguous. A majority of students, 58/66, completed the peer evaluation.

While it is difficult to determine the agreeability between student ratings of the same project, or if ratings were consistent, students appeared honest in their evaluations and comments. A sample of 
comments and ratings from students are shown in Tables 1 and 2 .

Table 1. Cycling Project Ratings and Comments

\begin{tabular}{|c|c|c|c|}
\hline \multicolumn{2}{|c|}{ Rating } & Project Desc. & Peer Comment \\
\hline \multirow{2}{*}{$\frac{2}{2}$} & 3 & Bicycle turn signal. & $\begin{array}{l}\text { I've seen rear turning signals } \\
\text { [for bikes] in Toronto already. } \\
\text { Therefore not original. }\end{array}$ \\
\hline & 5 & $\begin{array}{l}\text { Integrated bicycle } \\
\text { lock. }\end{array}$ & $\begin{array}{l}\text { Definitely new, surprising and } \\
\text { original. I worry about the } \\
\text { practicality. }\end{array}$ \\
\hline \multirow{2}{*}{$\frac{\mathscr{E}}{\stackrel{E}{E}}$} & 3 & $\begin{array}{l}\text { Automated bicycle } \\
\text { collision avoidance } \\
\text { system. }\end{array}$ & $\begin{array}{l}\text { High cost, limited problem } \\
\text { solution. }\end{array}$ \\
\hline & 4 & $\begin{array}{l}\text { Integrated bicycle } \\
\text { lock. }\end{array}$ & $\begin{array}{l}\text { Useful, but will have to be } \\
\text { developed further }\end{array}$ \\
\hline
\end{tabular}

Table 2. Retailer Project Ratings and Comments

\begin{tabular}{|c|c|c|c|}
\hline \multicolumn{2}{|c|}{ Rating } & Project Desc. & Peer Comment \\
\hline \multirow{2}{*}{$\begin{array}{l}\text { ᄅ } \\
\frac{0}{2} \\
z\end{array}$} & 3.5 & $\begin{array}{l}\text { Banana tree } \\
\text { umbrella/patio } \\
\text { table protector. }\end{array}$ & $\begin{array}{l}\text { I have seen banana tree } \\
\text { umbrellas used before, and this } \\
\text { was sort of innovative, but } \\
\text { seemed to copy that idea lot! }\end{array}$ \\
\hline & 5 & $\begin{array}{l}\text { Modular stackable } \\
\text { storage boxes. }\end{array}$ & $\begin{array}{l}\text { Boxes for storage exist, but this } \\
\text { one seems to solve storage } \\
\text { problems better than other } \\
\text { existing designs. }\end{array}$ \\
\hline \multirow{2}{*}{$\frac{\mathscr{E}}{\stackrel{\mathscr{E}}{\Xi}}$} & 3 & $\begin{array}{ll}\text { Configurable } & \text { and } \\
\text { modular desk. }\end{array}$ & Small surface area. \\
\hline & 4 & $\begin{array}{l}\text { Laundry storage } \\
\text { system. }\end{array}$ & $\begin{array}{l}\text { I like the separation. Movable } \\
\text { is useful. Rack integrated has } \\
\text { promise. Appears useful. }\end{array}$ \\
\hline
\end{tabular}

The experts also expressed that they thought it was appropriate and valuable to provide creativity feedback to the students.

We then performed several comparisons, including comparisons between peer novelty and usefulness ratings, and comparisons between peer evaluations, presentation and report grades, and expert rankings. Pearson's correlation coefficient $r$ was calculated to determine if relationships existed between any of the evaluations and grades. Separate analyses were performed for the retailer project and cycling project because of the different nature of the projects. As a general guide, correlation coefficients of $\pm 0.1, \pm 0.3$, and \pm 0.5 are considered small, medium and large correlations respectively, with 0 indicating no correlation [28]. Positive correlations indicate simultaneous increases or decreases in both variables. Negative correlations indicate an increase or decrease in one variable with the opposite occurring in the other variable. Table 3 shows the correlations between peer evaluated novelty and usefulness; Table 4 the correlations between presentation grades, report grades and peer creativity evaluations; and Table 5 the correlations between expert evaluations, presentation and report grades and peer evaluations.
Table 3. Correlations Between Novelty and Usefulness

\begin{tabular}{|c|c|c|c|}
\hline Measure & $\begin{array}{c}\text { Retailer } \\
\text { Project }\end{array}$ & $\begin{array}{c}\text { Cycling } \\
\text { Project }\end{array}$ & Overall \\
\hline $\begin{array}{c}\text { Novelty and } \\
\text { Usefulness }\end{array}$ & 0.45 & 0.38 & 0.40 \\
\hline
\end{tabular}

Table 4. Correlations Between Peer Novelty and Usefulness and Grades

\begin{tabular}{|c|c|c|c|c|}
\hline & \multicolumn{2}{|c|}{$\begin{array}{c}\text { Retailer Project } \\
\text { Peer Evaluation }\end{array}$} & \multicolumn{2}{c|}{$\begin{array}{c}\text { Cycling Project } \\
\text { Peer Evaluation }\end{array}$} \\
\hline Grade & Novelty & Usefulness & Novelty & Usefulness \\
\hline Presentation & 0.77 & 0.61 & 0.60 & 0.67 \\
\hline Report & -0.30 & 0.23 & 0.06 & 0.56 \\
\hline
\end{tabular}

Table 5. Correlations Between Expert Ranking, Grades and Peer Evaluations (Retailer Project)

\begin{tabular}{|c|c|}
\hline Measure & Expert Ranking \\
\hline Presentation Grade & 0.54 \\
\hline Report Grade & 0.82 \\
\hline Peer Novelty & 0.29 \\
\hline Peer Usefulness & -0.75 \\
\hline
\end{tabular}

Correlations between expert ranking and grades, and expert rankings and peer evaluations were calculated by first ranking groups based on grades, peer novelty or usefulness ratings, and then calculating the correlation with the expert ranking. The result is similar to calculating Spearman's rank correlation coefficient $\rho$.

\section{Discussion}

Overall, students and experts were accepting of the creativity evaluation and ranking processes despite the ambiguity of creativity. Student comments on peer evaluation sheets were honest and varied, which appear to indicate that students took the evaluation seriously.

The quantitative analyses showed some interesting relationships, some of which are supported by others' observations and the literature. Some of the analyses appear to highlight differences between engineering definitions of creativity and other definitions of creativity. These relationships and trends will be further discussed below.

The correlation coefficients between the creativity measures of novelty and usefulness, as determined by peer evaluation, show a medium positive correlation between novelty and usefulness, with the overall $r=$ 0.40 . This indicates there is a relationship between novelty and usefulness in terms of human judgements of creativity; at least within an engineering context. This is not surprising as many authors emphasize that creative artefacts must be both creative and useful [3][15], and [26] also observed a dependency between 
novelty and usefulness when evaluating creativity in electronics design. However, because it is not a perfect positive correlation, i.e., $r=1.0$, novelty and usefulness are not redundant measures, indicating they measure different dimensions of creativity.

In general, there was a large positive correlation between presentation grades and peer evaluation of both novelty $\left(r_{\text {retailer }}=0.77, r_{\text {cycling }}=0.60\right)$ and usefulness $\left(r_{\text {retailer }}=0.61, r_{\text {cycling }}=0.67\right)$. This shows a relationship between more creative designs and better presentations. However, we are unable to determine the causality of this relationship, i.e., do more creative designs result in better presentations, or do better presentations reflect more creative designs? Regardless, this relationship intuitively makes sense, and it supported by other work showing that the combination of high creativity and academic skills translate into improved design quality and innovativeness [12].

Next, correlation coefficients between report grade and peer evaluations of novelty $\left(r_{\text {retailer }}=-0.30, r_{\text {cycling }}\right.$ $=0.06)$ and usefulness $\left(r_{\text {retailer }}=0.23, r_{\text {cycling }}=0.56\right)$ do not show a consistent relationship between novelty and report grade, while showing a more consistent relationship between usefulness and report grade. The lack of correlation between novelty and report grade may show that novelty is unimportant within traditional evaluations of engineering design. While the lack of correlation between novelty and report grade is expected, it is unclear why there were large correlations between novelty and presentation grade, as both report and presentation grades are traditional methods of evaluating student outcomes. The positive correlation between design usefulness and report grade appears to emphasize the importance of usefulness within engineering design. So while this set of correlations does not show as clear a relationship between creativity and grade as previously seen with presentation grade, there does seem to be some relationship between grade and a component of creativity, i.e., usefulness.

Finally, we compared expert rankings of the retailer projects with presentation grade $(r=0.54)$, report grade $(r=0.82)$ and peer evaluations $\left(r_{\text {novelty }}=0.29\right.$, $\left.r_{\text {usefulness }}=-0.75\right)$. The large positive correlations between expert ranking and presentation and report grades show a relationship between higher grades, e.g., better content and organization of report and presentation, and more creative designs. This was also observed with the large positive correlation between presentation grades and peer creativity evaluations. The large negative correlation between expert ranking and peer evaluation of usefulness may indicate that experts and peers use different definitions of creativity, namely usefulness is prioritized differently between the two groups. This may reflect that the students are working within an engineering definition of creativity, while the experts were working within a product development and retailing definition of creativity. These differences in expert and peer definitions of creativity point to a need to select creativity evaluation methods carefully.

Overall, our experiences with evaluating design project creativity show that students accept expert and peer creativity evaluation and inclusion of the evaluation in the final grade. Our experiences also revealed some interesting relationships, some supported by others' work, e.g., relationship between novelty and usefulness, some supported by the literature, e.g., engineering emphasis on usefulness, and some which appear new, e.g., disagreements between expert and peer perceptions of creativity.

\section{Future Work}

We have shown that it is possible to evaluate design project creativity. However, other questions arise, such as: What are suitable methods for evaluating design project creativity? Is it even appropriate to evaluate design project creativity? The following future work will help answer these questions:

- Survey of design instructors - To understand how other engineering design instructors evaluate and grade creativity, a national or international survey can be conducted. This survey would ask if instructors explicitly evaluate creativity, the weighting of such an evaluation and method of evaluation.

- Controlled evaluation experiments - To better quantify some of our observations in this paper, more rigorously designed and controlled experiments could be conducted. This could include formal expert/student feedback.

\section{Concluding Remarks}

We were motivated to investigate design project creativity evaluation because of the importance of creativity in engineering design. Our experiences with peer creativity evaluation seem to show that a simple, yet structured approach, i.e., specifically asking students to rate novelty and usefulness, produces results that are honest and acceptable by the students. Overall our work and the work of others appear to support that creativity can be evaluated within a design course. Evaluating creativity outcomes may even be a valuable part of design education as it may be used to encourage students to think about creativity, and to consciously work towards creative design. 


\section{Acknowledgements}

The authors gratefully acknowledge the financial support of NSERC. We also wish to acknowledge the participation of the students and the industry experts.

\section{References}

[1] V. Hubka, W.E. Eder, Design Science- Introduction to the Needs, Scope and Organization of Engineering Design Knowledge, Springer-Verlag, London, UK, 1996.

[2] G. Pahl, W. Beitz, Engineering Design, a Systematic Approach, K. Wallace, L. Blessing, and F. Bauert, Trans., K. Wallace, Ed., 2/e., Springer-Verlag London Ltd., London, UK, 1996.

[3] D. Ullman, The Mechanical Design Process, Third Edition, McGraw-Hill, New York, NY, 2003.

[4] A. Hatchuel, B. Weil, C-K design theory: an advanced formulation, Res. Eng. Design, 2009, 19:181-192.

[5] N. Cross, Designerly Ways of Knowing, Springer-Verlag, London, UK, 2006.

[6] T. Kelley, J. Littman, The Ten Faces of Innovation. Doubleday, NYC, NY, 2005.

[7] U. Mahle, The Path to Invention, Mechanical Engineering, September 2007, vol. 129, no.9 g 37-38.

[8] A.F. Osborn, A.F., Applied imagination: principles and procedures of creative problem-solving, 3/e, Scribner, 1963.

[9] G.S. Altshuller and L. Shulyak, And Suddenly the Inventor Appeared: TRIZ, the Theory of Inventive Problem Solving, 2/e, Technical Innovation Center, Worcester, MA, 1996.

[10] E. De Bono, Serious Creativity, HarperCollins, NY, 1992.

[11] R. Penlington, Keep Your Students in the Dark - Don't Let Assessment Suppress Creativity, International

Conferences on Engineering and Product Design Education, New Castle Upon Tyne, UK, September 13-14, 2007.

[12] E. Shields, Fostering creativity in the capstone engineering design experience, ASEE Annual Conference and Exposition, Conference Proceedings, 2007.

[13] J.S. Gero, Computational Models of Creative Design, Chalmers Design Seminar, March 19, 2008, University of Toronto.

[14] J. Betz, Assessing creativity in architectural design: Evidence for using student peer review in the studio as a learning and assessment tool, ASEE Annual Conference, Austin, TX, June 14-17 2009, AC-2009-428.

[15] T. M. Amabile, 1983, The Social Psychology of Creativity, Journal of Personality and Social Psychology, 43: 997-1013.

[16] M.A. Boden, What is Creativity?, in M.A. Boden's (ed.) Dimensions of Creativity, The MIT Press, 75-117, 1994.

[17] T.B. Ward, S.M. Smith, R.A. Finke, Creative Cognition, in R.J. Sternberg's (ed.) Handbook of Creativity, Cambridge University Press, 1999.

[18] C. Charyton, J.A. Merrill, Assessing General Creativity and Creative Engineering Design in First Year Engineering Students, Journal of Engineering Education, 98/2:145-156, 2009.

[19] R. Fleisig, H. Mahler, V. Mahalec, Engineering Design in the Creative Age, Proceedings of CDEN 2009, Hamilton, Ontario, July 27-29, 2009.

[20] D. de Montigny, H. Smitherson, C. Wright, Teaching Engineering Design and Communication in First Year Using Rube Goldberg Projects, Proceedings of CDEN 2009, Hamilton, Ontario, July 27-29, 2009

[21] E.P. Torrance, Torrance Tests of Creative Thinking, Scholastic Testing Service, Inc., 1974.

[22] D.C. Brown, Guiding Computational Design Creativity Research, in ed. J. Gero's Studying Design Creativity, Springer, 2008.

[23] S.P. Besemer, D.J. Treffinger, Analysis of Creative Products: Review and Synthesis, Journal of Creative Behavior, 15:158-178, 1981.

[24] O. Akin, C. Akin, 1998, On the process of creativity in puzzles, inventions and designs, Automation in Construction, 7:123-138, 1998

[25] J.J. Shah, S.V. Kulkarni and N. Vargas-Hernandez, "Evaluation of Idea Generation Methods for Conceptual Design: Effectiveness Metrics and Design of Experiments", Journal of Mechanical Design, 2000, 122:377-384.

[26] S. Waks, M. Merdler, Assessing Creativity Aspects in Engineering Students' Project Work, International Conference on Engineering Education, July 21-25, 2003, Valencia, Spain.

[27] G. Plantanitis, R. Pop-Iliev, Design-Build Project Approach in a First Year Engineering Design Course, Proceedings of CDEN 2009, Hamilton, Ontario, July 27-29, 2009.

[28] A. Field, Discovering Statistics using SPSS, 2/e, Sage Publications, London, UK, 2005. 